SYDNEY CHAPMAN

RICHARD S. LINDZEN

\title{
ATMOSPHERIC TIDES
}

Thermal and Gravitational

This book is the first book to describe presentday knowledge of the atmospheric tides and thermal tides as gravitationally and thermally forced atmospheric waves. Attention is given to the history of the subject, the data, methods of data analysis, theory, and the mathematical methods involved in the theory. Current theory has proven quite effective in predicting or explaining many observations; however, the shortcomings of the theory and detailed suggestions for improving the theory are presented.

Finally, observations of and theoretical results for the role of daily variations in upper atmosphere dynamics are treated. Atmospheric daily variations have been a matter of great intellectual interest for centuries. In the upper atmosphere, they are of great practical importance as well. For the atmosphere as a whole tides and thermal tides are the simplest examples of planetary scale circulations.

\footnotetext{
D. REIDEL PUBLISHING COMPANY DORDRECHT-HOLLAND
} 